\title{
DEMOCRACIA EM TEMPOS DE VIGILÂNCIA UBÍQUA
}

\section{DEMOCRACY IN TIMES OF UBIQUITOUS SURVEILLANCE}

\section{RESUMO}

\section{Ricardo Monteagudo ${ }^{1}$}

Pretendemos analisar o impacto na democracia das ideias de Shoshana Zuboff em Na era do capitalismo de vigilância. As corporações digitais têm interesses pragmáticos e financeiros com a coleta de informações doadas de boa vontade pelos usuários de meios de comunicação digital e redes sociais. As instituições públicas e governamentais pretendem utilizar os dados para procurar potenciais criminosos e terroristas, contudo precisam obedecer a legislação de seus países. Já as corporações são empresas globalizadas e imperialistas que costumam considerar e, eventualmente, estabelecer novos critérios legislativos nos locais em que operam, sobretudo porque os serviços que oferecem são novos, são provenientes de inovações tecnológicas recentes. A soberania e a própria ideia moderna de povo perderam substância política perante o superpoder das corporações. Cada cidadão representa agora um dispositivo de controle no capitalismo de vigilância ao mesmo tempo em que comemora os benefícios da tecnologia. Big data e inteligência artificial reduzem dramaticamente as liberdades democráticas num espaço em que a promessa de liberdade havia fomentado esperanças futuristas e libertárias. Com isso, há um novo panorama conceitual para repensar as condições da democracia.

Palavras-Chave: contrato social, superávit comportamental, ideologia, governamentalidade

\begin{abstract}
We intend to analyze the impact of Shoshana Zuboff's ideas on democracy in In the Age of Surveillance Capitalism. Digital corporations have pragmatic and financial interests with the extraction of information freely donated by users of digital media and social media. Public and governmental institutions intend to use the data to search for potential criminals and terrorists, however they must comply with their countries legislation. Corporations, on the other hand, are globalized companies that tend to consider and, eventually, establish new legislative criteria in the places where they operate, especially because the services they offer are new, and from recent technological innovations. Sovereignty and the modern idea of people have lost political substance in the face of corporations' superpower. Every citizen now represents a control device in surveillance capitalism while celebrating the benefits of technology. Big data and artificial intelligence dramatically reduce democratic liberties in a space where the promise of freedom has encouraged futuristic and libertarian hopes. With that, there is a new conceptual panorama to rethink the conditions of democracy.
\end{abstract}

Keywords: social contract, behavioral surplus, ideology, governmentality

\footnotetext{
${ }^{1}$ Bacharelado em Filosofia em 1989, Licenciatura em Filosofia em 1992, Mestrado em Filosofia (Ética e Filosofia Política) em 1998 e Doutorado em Filosofia (Ética e Filosofia Política) em 2003, sempre pela FFLCH-Usp. Realizou estágio Pós-Doutoral na Université de Paris-1 Sorbonne em 2008-2009. Atualmente é Professor assistente Doutor II no Departamento de Filosofia da FFCM-Unesp, campus de Marília. Foi Chefe de Departamento, Coordenador do Conselho de Curso, Membro do Progrtama de Pós-Graduação e Representante Docente na Congregação. Mora em Marília/SP. Publicou A noção do legislador em Rousseau (2007) e Rousseau e a retórica (2021). Afiliação: UNESP. Lattes: http://lattes.cnpq.br/7421830722871903. Orcid: https://orcid.org/ 0000-0002-1881-7719 E-mail: ricardo.monteagudo@unesp.br
} 


\section{INTRODUÇÃO}

Ultimamente, novas noções têm surgido para tratar do impacto dos avanços tecnológicos sobre a natureza e a sociedade. A bomba atômica inaugurou o antropoceno. O computador permitiu automatizar o tratamento de informações e o celular fez de cada homem uma informação singular a ser digitalizada. O Estado e as empresas se apropriam desses recursos para ampliar seu alcance político e sua lucratividade. O smartphone e os pressupostos que o envolvem equivalem ao antropoceno da idade geológica para a vida política das pessoas. Não há grandiloquência suficiente para compreender o conjunto de mudanças que têm ocorrido nas últimas décadas para a humanidade. Queremos mostrar que o estado de direito liberal e a democracia representativa tal como o conhecemos nos séculos XIX e XX nunca mais serão os mesmos, e os impactos políticos e sociais disso.

Tomaremos como referência uma professora de administração e negócios da Universidade de Harvard chamada Shoshana Zuboff. Vamos fazer uma breve exposição da problemática para justificar um pouco esta perspectiva catastrofista do momento crucial que vivemos em nossa história e em seguida gostaria de analisar um pouco melhor apenas alguns aspectos da modernidade que não poderá prosseguir como esperávamos, especialmente o contratualismo e o estado de direito (1).

Zuboff nos interessa em particular porque no início de sua carreira de pesquisa, nos anos 70, ela analisava a mudança na gestão do trabalho com a introdução de computadores no dia-a-dia. Ela logo percebeu que a organização do trabalho do ponto de vista administrativo sofreria um impacto decisivo, pois não se tratava apenas de uma nova máquina para reduzir custos e otimizar ganhos, mais do que isso, tratava-se de uma máquina que permitiu melhor controlar os processos produtivos e administrativos. Ela observou que o controle da hierarquia, ou seja, do chefe sobre os trabalhadores e dos gerentes sobre os chefes e assim sucessivamente era muito maior, senão quase total. Assim, o interesse sobre a cibernética era mais do que econômico, era também e especialmente administrativo e concernia à política de crescimento da empresa. O poder da hierarquia e da concentração é total, ao menos sobre aquilo que interessa economicamente. Ora, ela notou então que este aspecto atrairia todas as atenções de setores e órgãos interessados em ter e exercer poder político. Sua atenção e suas pesquisas se desdobraram em dois aspectos: auxiliar as empresas a lidarem com esta novidade do ponto de vista prático (em $O$ novo jogo dos negócios, Maxim \& Zuboff 2003); e refletir sobre os impactos sociais destes novos procedimentos (em Na era da máquina inteligente, ZUBOFF 1988).

Cabe notar que, quando suas pesquisas começaram, em sua juventude, no final dos anos 70, ao publicar seus primeiros artigos, o computador pessoal ainda não existia (2). O IBM-PC jr, com 
64 kilobytes de memória e equipado com o DOS foi lançado em 1981. Curiosidade: a própria IBM não dava muita importância aos micro-computadores e o DOS, Disk Operating System, foi desenvolvido por dois adolescentes, um dos quais se chama Bill Gates, fundador da Microsoft, uma das principais corporações digitais do mundo hoje.

\section{Negócios, política e biopolítica}

Zuboff percebeu precocemente o novo jogo dos negócios. O computador passou a atrair mais investimentos do que a produção industrial e que sua função maior era administrativa: "A produção em massa e o capitalismo gerencial nasceram juntos (...) e encontram sua expressão comum na lógica empresarial padrão da atual abordagem à atividade comercial, que tem por objetivo gerar valor aravés da produção de mercadorias e serviços no espaço organizacional" (MAXIM \& ZUBOFF, 2003, p.21, grifo nosso). Com a expansão de mercados, os custos caem e os lucros aumentam. A tecnologia aumenta o "foco interno" na coordenação e o controle da produção e distribuição. A hierarquia permite manter sob controle órbitas sucessivas de acionistas, trabalhadores, clientes e consumidores, cada órbita fica alheia à outra sob controle estrito: "As pessoas não questionam pressupostos que não vêem mais". O computador permite reorganizar portanto inteiramente a lógica empresarial e isolar as zonas de conflito. Este processo se chamava reengenharia e abrangia e separava a produção em diversas regiões, se possível diversos países, justamente para enfraquecer a autonomia de cada órbita e aumentar o controle central.

Um dilema emergiu, as tecnologias baseadas em computadores não são neutras e as alternativas futuras de trabalho e poder estão se readaptando às crises abertas pelas novas formas de informação. O impacto destas transformações é enorme em todas as esferas da vida e do trabalho, ou seja, o exercício de poder passa por mudanças decisivas pelas quais o suporte humano perde o alcance para uma estrutura por assim dizer monstruosa. "Os gerentes empregam a tecnologia para contornar o compromisso do trabalho face a face e o substituem por técnicas de gerenciamento remoto e administração automatizada" (ZUBOFF 1988, p.7). Contudo, há um campo de batalha, pois esta mesma tecnologia permite "novos métodos de compartilhamento de informação e troca social (...) possibilita um profundo senso de responsabilidade coletiva e produção comum”. Justamente, nas últimas décadas, esta batalha se acirrou.

Nesse contexto, Zuboff aponta o potencial de ubiquidade dos computadores e menciona Foucault (ZUBOFF 1988, p.319) sobre o controle disciplinar presente no uso dos computadores e, especialmente, no panoptismo que a adoção desta ferramenta permite. Trata-se ainda de Vigiar e punir e da exposição que Foucault faz sobre Bentham, "um signo e uma metáfora do novo controle disciplinar". É interessante porque, como economista, é o aumento maquiavélico de ganho das empresas (e bancos) que interessa; mas, como pensadora, é a sociedade de controle e a 
reorganização do poder social e político que precisa ser refletida. De um lado, as garras do capitalismo (política); de outro lado, a subjetivação do poder (biopolítica). Amplia-se o controle do capital sobre o trabalho sob o método da governamentalidade apoiado por computadores, por dispositivos de controle.

Esse movimento nos mostra como o colapso da modernidade se deu por dentro do sistema, as generalizações formais se privatizaram de forma maquiavélica e irreversível. O controle é privado e o direito (liberal e moderno) de privacidade pouco a pouco se torna irrelevante, ou melhor, impossível. É o início do pós-modernismo na administração. Habituamo-nos no século XX a considerar o fenômeno da massa como uma referência de nossas reflexões: a massificação das artes, a industrialização massiva, o consumo de massa, o populismo de massa, e assim por diante. Agora, o controle é setorizado, individualizado, digitalizado, personalizado. A massa permanece, obviamente, mas não é o personagem principal das novas narrativas biopolíticas. Agora pode-se acompanhar e manipular cada grupo com alto grau de determinação. Acompanhamos o ritual de passagem entre a sociedade disciplinar e a sociedade de controle, da metáfora do panóptico do centro para fora, centrípeta, para a ubiquidade digital do panóptico, de fora para dentro, centrífuga (3). Ou seja, todo o capitalismo se transfigurou numa nova forma de acumulação: o consumo, valor-de-uso, que era o objetivo final da produção, agora é parte constitutiva do produto, uma mônada de informação que virou mercadoria.

Muito rápido? Ficamos atordoados? Sim, foi um processo muito rápido que nos deixou todos atordoados... Antes de Julien Assange com o Wikileaks, ou Edward Snowden, com a denúncia de documentos comprobatórios destas hipóteses, ou antes de Mark Zuckerberg com o Facebook, ou Larry Page e Sergey Brin, com a Google, tudo isso parecia futurismo ou teoria conspiratória. Shoshana Zuboff apontara que este caminho era inexorável e ambivalente, observara que os cidadãos não teriam tempo de assimilar todas as mudanças, sobretudo porque festejavam as vantagens oferecidas.

\section{CAPITALISMO DE VIGILÂNCIA}

Em seu mais recente livro, de 2019, A era do capitalismo de vigilância: a luta pelo futuro da humanidade numa nova fronteira do poder, Zuboff mostra que este movimento de informatização plena e total da vida está completo com o aumento das capacidades de armazenamento, o bigdata e a evolução da inteligência artificial. A empresa que melhor o simboliza é a Google porque foi pioneira em consolidar um avanço inadmissível até então, o fim total da privacidade (favorecido pelo impacto da queda das Torres Gêmeas em 2001). Há um caso exemplar da situação de abuso em que nos envolvemos à nossa revelia conhecido como "Spy-fi", que 
desencadeou inicialmente processos judiciais na Alemanha e nos EUA. O Google Maps mapeou toda a terra e ademais oferece um recurso fantástico, o Street View. Automóveis tomam as imagens in loco e as vinculam ao mapa. Gratuitamente! Mas este carro também toma os dados de todas as redes wi-fi de acesso doméstico à internet que ele reconhece nas vizinhanças. São dados com os quais o Google se ocupa e desenvolve cálculos complexos, qualifica e vende para as empresas para que elas reconheçam mais facilmente potenciais compradores de seus produtos. Fomos consultados? Não. Invasão de privacidade? Sim. Mas quando autorizamos o Google Maps em nossos dispositivos digitais, aceitamos as condições colocadas pela empresa para que possamos utilizar o software. As legislações dos diversos países são diferentes e eventualmente divergentes, logo há uma zona de tolerância jurídica para as grandes corporações transnacionais, economicamente importantes e poderosas, que se sentem à vontade para fazer certas adaptações em função de avanços tecnológicos ainda não agregados aos sistemas jurídicos, legislativos e deliberativos.

A fragilidade dos usuários de recursos digitais é intransponível. Como há várias situações análogas em quase todas as empresas de dados, teríamos que simplesmente não ter nem telefone nem conta bancária. Teríamos que nos isolar numa comunidade alternativa como Christiania, que recusa todo e qualquer eletricidade e aparelho eletrônico, em Copenhaguem, Dinamarca. É quase impossível não admitir "livremente" as condições, ou seja, estas condições nos são impostas. Mesmo que resistamos, alguém em nosso circuito social vai nos expor involuntariamente (4).

De forma análoga ao Street View, todas as grandes corporações digitais (as Big Tech, especialmente as Big Five, a saber, Amazon, Apple, Facebook, Google e Microsoft) guardam nossos dados e os utilizam para realizar negócios ou simplesmente nos manipular. Assim, nossas informações privadas viraram commodities, mas mais do que isso, viramos uma engrenagem na nova cadeia produtiva, que não se encerra mais no consumo e agora abrange nosso desejo futuro, como veremos.

O tempo da manipulação tal como nos habituamos a compreender com Noam Chomsky e a mídia impressa e televisiva já passou. Todos conhecemos, por exemplo, as análises de Chomsky sobre a manipulação da opinião pública pelas mídias, pelo viés das reportagens, pelo tempo e pelo espaço de exposição a informações insuficientes ou questionáveis do ponto de vista do bem público, e assim por diante (cf. CHOMSKY, 2003). Para a mídia digital, o mais correto seria o termo “modulagem" (cf. SILVEIRA 2018, p.38). Agora, não somos mais apenas manipulados, somos modulados. Nossos dados são utilizados para produzir nossos próprios desejos, posto que os dados são tratados por algoritmos que pretendem - e conseguem - direcionar nosso comportamento. Em outras palavras, a vigilância digital visa controlar de forma tão precisa quanto possível o comportamento futuro de cada um de nós. O capitalismo de vigilância hoje governa nosso 
comportamento, conduz nossa conduta, eis a forma melhor aperfeiçoada de governamentalidade, para retomarmos o termo e o conceito de Foucault (2008) num curso no Collège de France. Enquanto produzimos conteúdo gratuitamente para as redes sociais, nós também concedemos dados às empresas e órgãos públicos que se interessam por aspectos de nosso comportamento, de forma totalmente individualizada.

Vamos analisar agora alguns aspectos do pioneirismo da Google para apontarmos a partir daí uma série de consequências sobre as quais as ciências humanas e sociais precisarão se deter.

Zuboff analisa os textos de Hal Varian, economista informacional do Google, quando ele defende e justifica os serviços gratuitos do Google como prática de negócios. De fato, trata-se de uma preocupação técnica com impacto decisivo em nossa vida: tudo o que é mediado por computador é registrado e todos estes registros contribuem para melhorias significativas nas relações sociais, cognitivas, informacionais. Para ele, a mediação do computador torna tudo transparente e cognoscível por meio dos mecanismos de busca e produção de conhecimento. Em outro ponto, Varian fala em novas formas contratuais devido a um melhor monitoramento, personalização e customização. Dessa forma, diz ele por exemplo, se um carro financiado não for pago, ele pode ser facilmente localizado ou desligado; se o motorista dirigir de forma imprudente, a seguradora pode aumetar o valor da apólice; ou a frequência em bares e o consumo de bebidas alcoólicas podem indicar certo risco de envolver-se em problemas policiais ou dificuldades profissionais, etc. Hal Varian comemora como uma nova forma de contrato pela qual o contrato nunca seria quebrado, dado o monitoramento perfeito e completo de recursos informáticos (informação automatizada). Ao analisar a competência cognitiva irrestrita do computador e o controle material absoluto da pessoa, Zuboff afirma que, ao contrário do que pretende Varian, "o contrato se torna um incontrato" (ZUBOFF 2020, p.255), ou um descontrato (5).

Apoiada em vários pensadores sociais (Durkheim, Hannah Arendt, Weber), Zuboff mostra que a ideia de contrato existe para mitigar a desconfiança e permitir certa adaptabilidade a imprevistos ou novas necessidades incalculadas. De fato, o contrato se funda na promessa e na confiança dos contratantes. É por esse meio que a solidariedade orgânica se forma na sociedade. Com a vigilância absoluta dos dispositivos digitais, essa construção social de valores compartilhados se torna irrelevante, posto que o computador retira a incerteza do contrato, o risco do acordo. $\mathrm{O}$ aspecto fundamental do contrato se esvai porque o espaço da liberdade se anula. Justamente, diz Zuboff, a utopia do contrato perfeito retira a autoridade do contrato e o torna um problema meramente técnico. Diríamos, o homem agora fica como que robotizado, automatizado, ou melhor, uma formiga trabalhadora obediente ao zangão. Ela lembra Hannah Arendt: a falibilidade humana é o preço da liberdade (ZUBOFF 2018, p.43). Lembra Max Weber: as reivindicações garantidas por coerção legal permitem designar a sociedade contemporânea como 
sociedade contratual (ZUBOFF 2018, p.42). Ora, ao contrário, afirma Zuboff, "a visão de Varian de um mundo mediado por computador me soa como um deserto árido, não como uma comunidade de iguais vinculados pela luta humana contra a incerteza", um lugar "em que os últimos vestígios de confiança se esvaeceram e morreram". Diz ela, "o revigoramento humano a partir das falhas dá lugar ao vazio da submissão perpétua". O controle absoluto das pessoas faz com que elas deixem de ser pessoas e se tornem objetos. As pessoas perdem autonomia, não como objetos de um contrato, mas como imperiosamente submetidas a uma condição objetiva em que todos os riscos ficam apenas de um lado. O contrato se converte numa folha de mandamentos. O objetivo é garantir o lucro sem ônus da empresa. Podemos também imaginar rapidamente o que isto significa em termos de vida política.

\section{NOVO PODER SOBERANO}

Esta condição de monitoramento absoluto ela chama de "Grande Outro/Big Other" (6): "um ubíquo regime institucional em rede que registra, modifica e mercantiliza a experiência cotidiana, desde o uso de um eletrodoméstico até os próprios corpos, da comunicação ao pensamento, tudo para estabelecer novos caminhos para o lucro" (ZUBOFF 2018, p.43). Assim, a primeira observação trata da garantia da empresa privada, mas podemos perceber que a implicação é muito maior. Ela continua: "O Big Other é um poder soberano de um futuro próximo que aniquila a liberdade alcançada pelo estado de direito". Temos a configuração de um novo poder soberano que rompe a tradição contratualista moderna (7).

De fato, se o computador permite tornar tudo previsível e calculado, se ele antecipa, modula, conforma, se tudo se reduz a planejamento condicionado de estímulos-resposta, não há mais liberdade. A autonomia é irrelevante e a autodeterminação psicológica é uma ilusão. Diz ela, "as pessoas são reduzidas a animais, inclinadas a servir as leis do capital por meio da alimentação implacável de registros ubíquos em tempo real, baseados em fatos de todas as coisas e criaturas" (ZUBOFF 2018, p.45). Adiante, afirma que "o capitalismo de vigilância estabelece uma nova forma de poder em que o contrato e o estado de direito são suplantados por recompensas e punições de outro tipo". É esse "outro tipo" que precisamos buscar entender. É ele que explica o negacionismo científico, o terraplanismo, a pós-verdade, as fake-news e também o lawfare em sua forma recente.

Ao lado de tanto narcisismo biopolítico, as pessoas não se sentem mais acolhidas ou abrigadas pelo sistema tradicional de instituições, pelo estado de direito, e passam a admitir coisas absurdas como se fossem normais, um novo normal. Ora, nesse novo normal, a representação da verdade entrou em colapso. O compromisso é uma promessa: se perdermos o compromisso metafísico, ético, político, estético e cognitivo com a veracidade, se permanecermos refém destes 
processos de modulagem do comportamento, então é o fim da humanidade tal como a conhecemos (8).

Observamos então que o contratualismo ou a noção de justiça moderna tal como nos habituamos entrou em colapso e precisamos repensar. As pessoas, assim como as instituições, são controladas pelas grandes corporações digitais, que manipulam o futuro para amplificar seus lucros. Temos uma espécie de neo-feudalismo, uma vez que se tratam de empresas privadas que escapam do controle público e transcendem as soberanias nacionais. A forma que a crise da democracia liberal tomou nos últimos anos é um efeito imediato destas constatações.

\section{CONTRATUALISMO MODERNO}

Vamos analisar brevemente alguns aspectos da modernidade para mostrar que nossos valores envelheceram e caducaram. Obviamente não é simples explicitar os meios pelos quais isto ocorreu, mas é certo que o computador, a internet e o big data são seu suporte técnico, o que também pode ser chamado de revolução digital ou microeletrônica.

As três principais formas do contratualismo moderno, Hobbes, Locke e Rousseau, concordam com os princípios de equidade, reciprocidade e utilidade públicas. A condição natural do homem anterior à civilização é submetida ao direito natural no estado de natureza, que por sua vez não é suficiente para a vida social e política. Forma-se o Estado, ou Corpo Político, por meio de um contrato que regula a convivência humana e estabelece leis e ordens que precisam ser obedecidas. Leis morais e políticas que abrangem a união social e os conflitos de interesses. O Corpo político se organiza por instituições assim como o corpo natural divide suas atividades pelos diversos órgãos. As instituições têm finalidades que as justificam e articulam com todo o tecido social. Individualmente, as pessoas estão inseridas nas instituições que formam as pessoas e são formadas por elas. Assim, aquela multidão heterogênea e disforme adquire por meio do contrato e das instituições uma unidade que se manifesta na soberania do Estado e em seu sistema legislativo.

As leis precisam por isso ser equânimes e eventuais privilégios precisam estar previstos na legislação. Todos são iguais perante a lei, exceto nos casos em que a desigualdade tenha sido previamente estabelecida. Isto é o que garante o contrato, caso contrário o contrato não orientaria interesses heterogêneos, não reuniria a multidão dispersa como povo organizado. O contrato unifica as vontades no soberano. Pela mesma razão, as leis exigem reciprocidade, ou seja, tudo o que é autorizado para um cidadão deve ser autorizado para todos os outros dentro das mesmas condições legalmente estabelecidas. Se um homem tem um direito, todos os outros terão o mesmo direito na mesma condição, caso contrário o contrato não poderia determinar direitos e deveres ao conjunto dos cidadãos. Além disso, a utilidade pública tem que ser preservada para evitar tanto a intromissão 
do Estado em questões privadas como para permitir a livre iniciativa dos cidadãos no que não está regulado em lei ou protegido por direito natural.

A modernidade se moldou com esta concepção de contrato social, independente das nuanças de um Governo mais forte em Hobbes, ou de uma economia política mais operante em Locke, ou de uma soberania popular mais ativa em Rousseau. A noção de contrato tem origem no direito romano medieval, em relações privadas independentes do Estado, ou seja, uma origem comercial. Por isso dizemos que é a multidão de indivíduos que se reúne no contrato para formar um povo de cidadãos. Assim, a preservação dos interesses individuais no contrato é uma das principais condições para que o esforço moral e político de união soberana se justifique. Justamente é a sobrevalorização do indivíduo que emerge com a modernidade cartesiana do cogito e sua expressão moral e política posterior com o jusnaturalismo e com o contratualismo. Ou seja, se o interesse coletivo dos indivíduos não for preservado, a ideia de contrato se torna contraditória.

Aqueles que participam do contrato são indivíduos que se comprometem em obedecer regras sociais e concordam implicitamente em ser punidos caso não o façam. Sem o compromisso do indivíduo, não há contrato. $\mathrm{O}$ compromisso por sua vez está fundado na promessa pessoal de conduta futura e na confiança ou fé de que as outras pessoas manterão seu compromisso. Seja por medo, por interesse ou por consciência, o compromisso depende da promessa e da fé. Este aspecto é crucial: abelhas e formigas não são sociais por compromisso mas por natureza. Assim, o compromisso é justamente o lugar da liberdade nas relações humanas. Eu me comprometo porque eu acredito. Ora, se supormos que o compromisso é desnecessário, as relações humanas se naturalizariam, a liberdade não estaria pressuposta, os homens se tornariam sociais como abelhas e formigas, obedeceriam como animais domesticados ou escravos da natureza. Pode parecer uma sutileza metafísica, mas todo o estado de direito contemporâneo está fundado nesta hipótese. Sem comprometimento, sem promessa e confiança, os humanos se tornam bestas ferozes ou personagens sádicos. Seus apetites animais se imporiam a seus deveres morais, não haveria ética, ou por assim dizer não há contrato. Mais que isso, não haveria sequer finalidade para nada, não haveriam interesses racionais ou conscientes.

\section{SUPERÁVIT COMPORTAMENTAL}

Voltemos a Shoshana Zuboff para conferir algumas de suas análises sobre os contratos que somos obrigados a assinar virtualmente para termos autorização para utilizarmos os softwares proprietários das grandes corporações digitais, as Big Techs. Antes uma pequena observação: em 2008 dois professores calcularam que uma leitura razoável de todas as políticas de privacidade exigidas pelos softwares que uma pessoa utiliza durante um ano exigiria 76 dias de trabalho 
(ZUBOFF 2020, p.66). Hoje certamente este valor é maior. Esse é o tempo que demoraríamos para ler e compreender (e provavelmente discordar impotentes) os contratos embutidos nos dispositivos eletrônicos de vigilância que tornam nosso dia a dia mais confortável.

Precisamos antes entender de que forma as Big Tech devassam nossa privacidade e com qual interesse. Os jovens da Universidade de Stanford criadores do Google descobriram o que Zuboff chama de superávit comportamental (behavioral surplus). Quando fazemos buscas no Google, utilizamos certas palavras e o sistema nos oferece resultados. Cada clique nos resultados recebidos, o tempo entre os cliques, o tempo de permanência nas páginas (home-pages) ofertadas, o conteúdo das páginas, o link (vínculo entre as home-pages) anterior, o link seguinte, nossa reação catalogada nos dispositivos, tudo é meticulosamente armazenado. Há uma grande quantidade de dados armazenados que não tem relação com a pesquisa pelo usuário. O objetivo inicial era melhorar a experiência do usuário. Os algoritmos de inteligência artificial começaram a reconhecer certas uniformidades nas reações, nos tempos, nas escolhas. Estas uniformidades provinham dos conteúdos das páginas, mas também dos tempos, dos caminhos entre os links, da disposição das alternativas. Uma parte relevante de dados obtidos - que não serviam para "nada" - estava disponível para estudos. Este é o superávit de dados extraídos que denuncia aspectos de nosso comportamento. Com isso, perfis de usuários foram classificados e catalogados, seus cliques podem ser condicionados e estimulados ou desestimulados pela forma como os resultados são oferecidos, suas ações podem ser encorajadas ou deprimidas, suas emoções podem ser desencadeadas, amplificadas ou destorcidas, suas opiniões podem ser conduzidas ou incutidas. Recursos de bigdata e inteligência artificial permitem discriminar perfis por interseção e cada indivíduo singular pode ter sua conduta futura calculada e prevista. O Google vende a informação do futuro de seus usuários para publicidade e para governos. Este lucro exorbitante (financeiro e político) com o futuro previsto é o que Zuboff concebe como um novo estágio do capitalismo, o capitalismo de vigilância.

Esse passo a mais entre o objetivo bem-intencionado de auxiliar o usuário em suas buscas e o objetivo comercial de monetizar os metadados (dados acrescidos à informação que não lhe dizem respeito diretamente) entregues pelos usuários foi tão importante para o Google que Zuboff o qualifica como "estado de exceção". Jovens geniais de universidades americanas fundavam startups e recebiam financiamentos vultosos para suas descobertas e iniciativas. Alguns poucos empreendimentos cresceram com os bons resultados financeiros e outros muitos bastante interessantes se paralisaram por sua falta. A diferença entre sucumbir como muitos ou crescer como poucos era dar retorno monetário, lucro, aos investidores e acionistas. Os jovens do Google precisavam deixar o idealismo utópico e libertário da internet para sobreviver e ganhar dinheiro, um salto qualitativo maior. Precisaram refletir em como utilizar estes metadados guardados para gerar lucro. 
A descrição da descoberta é significativa: um dia, observaram um aumento notável de buscas por uma questão irrelevante, "qual o nome de solteira de Carol Brady" (ZUBOFF 2020, p.94), a cada 48 minutos por 5 horas. Tratava-se de um programa de auditório televisivo apresentado em cada um dos 5 fusos horários dos EUA. A surpresa era a uniformidade das buscas e reações. A primeira vez chamou a atenção. A segunda vez confirmou a primeira. A terceira a quarta e a quinta repetiram as duas primeiras, ou seja, poderiam ter sido previstas. Foi aí que se notou cientificamente, matematicamente, que a antecipação do desejo do usuário poderia ser calculado. E mais do que isso, pelos princípios de economia comportamental, o desejo do usuário poderia ser direcionado, conduzido e até mesmo executado (por exemplo, manifestações de intolerância nas redes sociais). Notemos contudo que não se trata de um cálculo de manada ou previsão por amostragem, mas previsão e condução científica por algoritmos de desejos e emoções, ações e reações praticamente individuais com excepcional grau de acerto de prognósticos.

Num primeiro momento, a extração de nossos metadados tem a finalidade de aperfeiçoar os programas de busca, num segundo momento estes metadados configuram um superávit de comportamento que permite calcular nosso futuro, um devir que pode ser vendido. Em 2002, o Google valia 37 milhões de dólares, em 2014 ultrapassou a Exxon Mobil e se tornou a maior empresa do mundo com capitalização de 400 bilhões de dólares em apenas 12 anos (cf. ZUBOFF 2020, p.114). A diferença de custos e a proporcionalmente pequena quantidade de trabalhadores envolvidos permite a Zuboff indicar que o capitalismo entrou em uma nova fase, informacional, diferente da fase fordista anterior, industrial.

Pois bem, retomemos a curiosa expressão estado de exceção, quando os jovens perderam o idealismo e decidiram utilizar os metadados com finalidades expansionistas. Algumas tentativas de invasão de privacidade por iniciativa de outras empresas ocorreram nos anos 90, mas houve resistência política e jurídica. Somente com os avanços técnicos do Google o salto magistral permitido pelo big data foi possível. Queremos analisar brevemente o suporte jurídico dessa decisão.

A forma pela qual os metadados são coletados e utilizados são segredos tecnológicos patenteados e protegidos criteriosamente pela empresa, seus funcionários são ameaçados implacavelmente se passam informações, mesmo quando instados por pesquisadores universitários com finalidades acadêmicas. São proibidos por contrato (ZUBOFF 2020, p.81). Zuboff recorre então aos documentos oficiais em que a Google apresenta seus serviços e defende a legitimidade de sua função. O economista da Google, Hal Varian, também conhecido como "Adam Smith da Googlenomia" (ZUBOFF 2020, p.81), apresenta os produtos e justifica a vantagem perante outros canais concorrentes que tendem a fazer o mesmo. Contratado para ampliar os ganhos da empresa, percebeu que a mineração dos dados dos usuários poderia gerar subprodutos: "Toda ação realizada 
por um usuário é considerado um sinal a ser analisado e realimentado no sistema" (ZUBOFF 2020, p.84). Num primeiro momento, os dados comportamentais eram usados em favor do usuário; num segundo momento, como vimos, as buscas passaram a se combinar com anúncios publicitários, e em seguida, com a força do superávit comportamental, os interesses dos usuários passaram a ser dirigidos. Criou-se um mercado futuro de desejos e interesses. Com isso, o que Zuboff chama de estado de exceção, houve quebra de reciprocidade, posto que os metadados permitem ao sistema retirar do usuário mais do que ele pretende conceder em troca da gratuidade das consultas. É a destruição total da privacidade para muito além do que cada indivíduo pode sequer imaginar. A transparência fica de um lado e o poder opaco de outro. Para cada usuário se estabelece uma informação de perfil de usuário (UPI, user profile information). Métodos computacionais permitem inferir, presumir e deduzir características de personalidade e escolhas pessoais, individualmente. Contudo, para alcançar este resultado é preciso desconsiderar, ignorar que o conflito relacionado aos direitos de escolha de cada um não é uma questão técnica, mas ao contrário, é um problema social e psicológico, implica em combalir a autonomia, há sérios e graves dificuldades éticas envolvidas.

O superávit comportamental inclui dados que o usuário não pretende compartilhar. Estes metadados têm custo zero e por isso "permitem uma operação de mercado altamente lucrativa" (ZUBOFF 2020, p.101). Segundo Zuboff, "nenhuma restrição moral, jurídica ou social vai impedir a empresa de encontrar, reivindicar e analisar o comportamento alheio" (ZUBOFF 2020, p.99). Os verdadeiros clientes da empresa Google não são os usuários. O Google transforma "a falta de clareza inerente ao desejo humano em fato científico (...) e estebelece valores e metas acima e além dos contratos sociais aos quais os outros precisam se submeter". Ora, o contrato que o usuário assina é na verdade um descontrato.

Este é um dos aspectos. Há outro mais decisivo: o contrato pressupõe uma cooperação entre os contratantes, um ideal de respeito e consciência entre as pessoas que eventualmente podem ser punidas pelo destrato ou pelo não cumprimento, mas mesmo assim o contrato não é um sistema de coerção. Se nos lembrarmos de Hobbes, o medo, a esperança e o desejo são as paixões que favorecem o pacto social (Leviatã, capítulo 13), não temos a coerção instantânea e mecânica de pessoas naturalmente livres. Os contratos são, por assim dizer, incompletos. É o que garante a equanimidade, ambos os contratantes, ambos os lados da relação contratual ganham se tudo der certo, ou ambos perdem se alguma coisa der errado. Hal Varian defende a hipótese de uma nova forma de contrato em que as pessoas são rigorosamente monitoradas e por isso o risco do descumprimento é nulo, não há incerteza. Por isso Zuboff chama de descontrato, pois as promessas humanas são abandonadas e substituídas "por cálculos positivistas de processos de máquina automatizados" (ZUBOFF 2020, p.381). Trata-se de uma distopia, os imperativos econômicos do 
capitalismo de vigilância. O cerne do descontrato "transforma os riscos humanos, jurídicos e econômicos dos contratos em planos traçados, monitorados e mantidos por firmas privadas em nome de resultados garantidos" (ZUBOFF 2020, p.382).

\section{IDEOLOGIA E GOVERNAMENTALIDADE}

Uma questão que nos interessa especialmente, a convergência de governamentalidade e ideologia, pode pressupor uma reconsideração de como as economias de mercado são consideradas. Normalmente, trata-se de relacionar a natureza, o trabalho e o dinheiro para a geração de mais valia. Com a vigilância, há um quarto aspecto a considerar: o comportamento. O capitalismo agora mercantiliza o comportamento. A biopolítica, ou seja, a condução da conduta, não é mais apenas uma questão de poder, mas uma fonte de lucro.

\section{LAWFARE}

Se nos é permitido chamar atenção para uma implicação maior, todas as situações de contrato sem risco adquirem outro âmbito. Este é, por exemplo, o sistema do lawfare, o que independe do contrato, pois a finalidade é a perseguição política, então o mesmo crime, a mesma infração, tem uma aplicação biopolítica a depender do jogo de poder. O risco fica de um lado só, independentemente do objeto em disputa, do conflito em questão. O contrato social não funciona mais como mediador, mas como aparelho, como dispositivo em defesa do mais forte em determinada situação ou contexto. Para além do uso ideológico da Justiça, queremos aqui indicar uma nova realidade introduzida para cada cidadão, para cada usuário do Google. Fala-se por exemplo na criação de dossiês para chantagear atores políticos ou atingir objetivos empresariais (9). Pode-se argumentar que isso sempre ocorreu em política desde sempre, o processo contra Sócrates, as filípicas de Cícero, mas agora o alcance é por assim dizer total. Ou seja, o lawfare se tornou um instrumento corriqueiro do imperialismo vigilante.

\section{GRANDE OUTRO}

Com o escândalo do Spi-fy, a descoberta na Alemanha e nos EUA de que o Google espionava as redes domésticas de wi-fi (ZUBOFF 2020, p.171), o Google foi acusado pela promotoria de se tornar um "Big Brother", Grande Irmão, conforme expressão do romance de George Orwell. De fato, a ubiquidade digital é hoje inevitável. Zuboff contudo prefere outra designação, “Big Other", Grande Outro. Segundo ela, o totalitarismo contido no Big Brother é uma 
transformação do Estado num projeto de possessão global, mas observamos que o Google é uma corporação privada que pretende "transformar o mercado num projeto de certeza total" (ZUBOFF 2020, p.433). Em outro lugar, num ensaio publicado em coletânea sobre tecnopolítica (BRUNO, CARDOSO, KANASHIRO, GUILHON, MELGAÇO, 2018), as implicações macro e micro políticas deste sistema digital ubíquo aparecem de forma mais incisiva, as implicações ideológicas são melhor discutidas. A sociedade de massa foi simbolizada pelo comando e controle centralizado do Big Brother. Nesse caso era possível escapar do controle quando nos afastávamos dos lugares em que ele se exercia. Essa possibilidade não existe com o Big Other, segundo a autora, devido aos "efeitos arrepiantes da conformidade antecipatória" (ZUBOFF 2018, p.45). Não é mais a massa, não há rotas de fuga, o controle é pessoal. Com isso, os indivíduos de um grupo passam a se reforçar a partir da modelagem individual, singular, a partir da qual o grupo coletivo se conforma. A experiência modelar encontra respaldo em outros indivíduos que tiveram estímulos análogos, embora não idênticos, com isso o grupo reforça a modelagem. Esse é o movimento da pós-verdade. O trabalho de antecipação é feito por um novo tipo de automaticidade, "uma experiência real baseada puramente em estímulo-resposta". A conformidade não é mais uma ação (ou inação), mas um resultado, não é mais uma causa, mas um efeito. O caminho, afirma ela, “já é moldado pelos interesses financeiros e/ou ideológicos que imbuem o Big Other e invadem todos os aspectos da 'vida privada' de cada um” (ZUBOFF 2018, p.45). Ou seja, o capitalismo de vigilância impõe a cada um seus próprios medos e desejos, uma ideologia dispersa e fragmentada que opera como governamentalidade e que pode ser compreendida como reunificada e unívoca.

A vontade modelada do grupo tem origem na vontade fragmentada dos indivíduos, opera de forma unificada com uma finalidade fugaz e em seguida se fragmenta novamente assim que o objetivo é alcançado. A memória do objetivo mantém a mobilização eventual, mas a origem fragmentada não desaparece e preserva o estímulo-reforço inicial. Em termos modernos, institui-se uma opinião metafísica que mobiliza uma pessoa moral coletiva que exerce uma função objetiva e que em seguida se desinstitui, se desmobiliza, se desfaz; mas a memória do sucesso preserva a capacidade de uma nova mobilização, uma nova operação, novamente com origem individual fragmentada. Diríamos que se trata da união perfeita entre a governamentalidade e a ideologia. É a nova ordem neo-liberal sob os auspícios da revolução digital.

Houve há alguns anos uma brincadeira social que pode ter sido uma experiência bem sucedida desse processo, ou ao menos o ilustra bem, os flash mobs (10). Pessoas que não se conheciam combinavam uma performance artística pelas redes sociais, geralmente o Facebook. Em determinada hora e lugar, todos cumpriam uma determinada tarefa por um tempo curto e em seguida voltavam a se dispersar. Assim se divertiam. Por exemplo, numa praça em certo horário, eles ficavam de quatro patas e imitavam cães por 2 minutos; em seguida recuperavam o comportamento 
normal, riam e se dispersavam novamente. Há assim uma operação de 2 minutos que atinge seu objetivo. A memória do sucesso mantém as pessoas mobilizadas para outra brincadeira em outro momento.

Uma forma de proteger parcialmente a privacidade é a criptografia e softwares livres para que as pessoas possam compreender e combater os efeitos nefastos seja do neo-totalitarismo (Big Brother) digital do Estado seja do neo-feudalismo digital das Big Techs (Big Other). Assim ao menos um caminho paralelo ao do controle do futuro estará aberta para a sociedade se defender da robotização total ("máquinas de certeza", cf. ZUBOFF 2020, p.499) e procurar formas efetivas de democratização (11).

Por outro lado, a introdução de novos elementos na democracia e na comunicação é animador, como a proposta de se eleger coletivos, isto é, representantes de discussões e deliberações promovidas por sitios (sites) ou páginas (home-pages), ou mesmo formas de deliberação direta, democracia direta por meios digitais. Contudo, mesmo assim alguém terá que preservar o controle tecnológico destes recursos. Ademais, o estado de direito, ou seja, o sistema jurídico em suas diversas instâncias (municipal, nacional, internacional, etc) terá que se refundar, reconstituir-se, reorganizar-se. Consideramos que o sistema jurídico moderno, para se defender das ameaças pósmodernas, precisa se proteger da possibilidade de lawfare e do abuso de fake-news; ou talvez se readequar a uma condição pós-moderna fragmentada sem perder a noção de Justiça que nos permite permanecer seres racionais e livres.

O Big Other propicia, por meio do big data proveniente de sensores, celulares (smartphones), televisões (smart tv) e outros dispositivos de captura de dados, "os olhos e ouvidos de um organismo vivo global a partir de um ponto de vista de Deus" (ZUBOFF 2018, p.55). O capitalismo de vigilância estabelece, assim, um novo tipo de poder soberano. Como se trata de um poder privado e desigual, podemos acrescentar que ele implanta um neo-feudalismo.

\section{À GUISA DE CONCLUSÃO}

Como observa Zuboff, "a democracia não é mais um meio para a prosperidade”, como fora durante a modernidade do contrato social e do estado de direito, como fora na sociedade de massa, mas ao contrário, a democracia "ameaça as receitas de vigilância” (ZUBOFF 2018, p.59). Podemos agora entender melhor a crise da democracia liberal, pois ela não poderá mais permanecer da mesma forma. As corporações digitais, as redes sociais, o bigdata, os algoritmos de inteligência artificial, em certo sentido o fim da sociedade de massa, que agora convive com o individualismo digitalizado, são obstáculos que impedem a democracia representativa liberal de sobreviver sem se refundar. 


\section{NOTAS}

1. Há dois documentários que tratam do assunto que desenvolveremos aqui: O dilema social (2019), que explora as ideias de Shoshana Zuboff que discutimos aqui; e Privacidade hackeada (2018), que aborda a manipulação das eleições nos EUA de 2016 pela empresa britânica de análise de dados Cambridge Analytica, também no livro KAISER 2020.

2. Há uma interessante e didática exposição sobre "a interdependência entre o contexto sócio-político-econômico e o desenvolvimento da tecnologia" (FERNANDEZ \& YOUSSEF 1985, p.28), sobre os primórdios da industrialização e da informatização e seus impactos sociais em relação à concentração de poder e possibilidades democráticas. Esse é o dilema a partir do qual Zuboff aponta uma reconfiguração total do capitalismo no século XXI.

3. A metáfora do panóptico é de Foucault a partir de Bentham e ilustra a noção de governamentalidade. Com os dispositivos de controle computadorizados, Zuboff amplifica esta noção para uma nova forma de capitalismo.

4. A impossibilidade de nos defender deste tsunami tecnológico foi apontada por Bria \& Morozov, 2019: A cidade inteligente.

5. Há uma hesitação na tradução do livro ZUBOFF 2020 e do ensaio ZUBOFF 2018 entre “descontrato" e "incontrato".

6. A tradução do livro (ZUBOFF 2020) utilizou "Grande Outro", mas a traduçao do artigo (ZUBOFF 2018) preservou o termo inglês "Big Other", onde fica mais clara a contra-posição com "Big Brother".

7. Como no caso das eleições dos EUA de 2016, conforme o documentário Privacidade hackeada e o livro Manipulados (KAISER 2020).

8. O filme $O$ dilema social, inspirado nas ideias de Shoshana Zuboff, no qual ela também aparece, desenvolve bem este tema.

9. Para indicarmos uma ocorrência pública com efeitos decisivos conhecido por todos, a presidente Dilma Roussef reclamou da espionagem na Presidência e na Petrobrás, comprovadas pelas denúncias de Edward Snowden. Podese conferir em <https://noticias.uol.com.br/internacional/ultimas-noticias/2013/09/24/na-onu-dilma-chamaespionagem-americana-de-violacao-dos-direitos-humanos.htm >, consultado em 30/06/2021.

10. Uma breve descrição em <https://pt.wikipedia.org/wiki/Flash_mob> (consultado em 30/06/2021).

11. Zuboff discute aí um "Novo Acordo" em função da morte da individualidade, para a qual a criptografia de dados e criptomoedas poderiam ser uma alternativa descentralizadora, mas "tanto exprimem quanto contribuem para a erosão generalizada do tecido social" (ZUBOFF 2020, p.498), ou seja, tencionam o dilema da transparência. Contudo a análise de um novo contrato social depende das pessoas envolvidas, uma longa discussão para outra ocasião.

\section{REFERÊNCIAS BIBLIOGRÁFICAS}

ARENDT, Hannah. A condição humana. São Paulo, Forense universitária, 1995.

BRUNO, Fernanda \& CARDOSO, Bruno \& KANASHIRO, Marta \& GUILHON, Luciana \& MELGAÇO, Lucas (org). Tecnopolíticas da vigilância. São Paulo, Boitempo, 2018.

CHOMSKY, Noam. Contendo a democracia. Rio de Janeiro, Record, 2003.

FERNANDEZ, Vicente Paz \& YOUSSEF, Antonio Nicolau. Informática e sociedade. São Paulo, Ática, 1985.

FOUCAULT, Michel. Segurança, território e população. São Paulo, Martins-Fontes, 2008.

FOUCAULT, Michel. Vigiar e punir. Petrópolis, Vozes, 1987.

HOBBES, Thomaz. Leviatã. Coleção Os Pensadores. São Paulo, Abril, 1973.

KAISER, Brittany. Manipulados. Rio de Janeiro, Harper Collins, 2020. 
LOCKE, John. Segundo tratado sobre o governo civil. Coleção Os Pensadores. São Paulo, Abril, 1973.

MAXMIN, James \& ZUBOFF, Shoshana. O novo jogo dos negócios. Rio de Janeiro, Campus, 2003.

MAXMIN, James \& ZUBOFF, Shoshana. O novo jogo dos negócios. São Paulo, Campus, 2002.

ROUSSEAU, Jean-Jacques. Contrato social. Coleção Os Pensadores. São Paulo, Abril, 1973.

SILVEIRA, Sérgio Amadeu da. "A noção de modulação e os sisyemas algorítmicos". In: AVELINO, Rodolfo \& SOUZA, Joyce \& SILVEIRA, Sérgio Amadeu da. A sociedade de controle. São Paulo, Hedra, 2018.

SOUZA, Joyce \& AVELINO, Rodolfo \& da SILVEIRA, Sérgio Amadeu (org). A sociedade de controle. São Paulo, Hedra, 2018.

ZUBOFF, Shoshana. "Big Other: capitalismo de vigilância e perspectivas para uma civilização de informação" in: BRUNO, Fernanda \& CARDOSO, Marta \& GUILHON, Bruno \& KANASHIRO, Luciana \& MELGAÇO, Lucas (org). Tecnopolíticas da vigilância. São Paulo, Boitempo, 2018.

ZUBOFF, Shoshana. A era do capitalismo de vigilância. Rio de Janeiro, Intrínseca, 2020.

ZUBOFF, Shoshana. In the age of the smart machine. NewYork, Basic books, 1988.

\section{Filmografia}

O dilema das redes (2020). [The social dilemma]. Direção: Jeff Orlowski. Distribuição: Netflix. Privacidade hackeada (2019). Direção: Jehane Noujam \& Karin Amer. Distribuição: Netflix. 